\title{
BMJ Open Neurodevelopmental disorders among term infants exposed to antenatal corticosteroids during pregnancy: a population-based study
}

\author{
Nir Melamed, ${ }^{1}$ Elizabeth Asztalos, ${ }^{2}$ Kellie Murphy, ${ }^{3}$ Arthur Zaltz, ${ }^{1}$ \\ Donald Redelmeier (D) , ${ }^{4}$ Baiju R Shah, ${ }^{5}$ Jon Barrett ${ }^{1}$
}

To cite: Melamed N, Asztalos E, Murphy K, et al. Neurodevelopmental disorders among term infants exposed to antenatal corticosteroids during pregnancy: a populationbased study. BMJ Open 2019;9:e031197. doi:10.1136/ bmjopen-2019-031197

- Prepublication history and additional material for this paper are available online. To view these files, please visit the journal online (http://dx.doi. org/10.1136/bmjopen-2019031197).

Received 21 April 2019 Revised 30 July 2019 Accepted 18 September 2019

Check for updates

(C) Author(s) (or their employer(s)) 2019. Re-use permitted under CC BY-NC. No commercial re-use. See rights and permissions. Published by BMJ.

${ }^{1}$ Obstetrics and Gynecology, Sunnybrook Health Sciences Centre, Toronto, Ontario, Canada ${ }^{2}$ Department of Newborn \& Developmental Paediatrics, Sunnybrook Health Sciences Centre, Sunnybrook Research Institute, University of Toronto, Toronto, Ontario, Canada

${ }^{3}$ Obstetrics and Gynecology, Mount Sinai Hospital, Toronto, Ontario, Canada

${ }^{4}$ Medicine, University of Toronto, Toronto, Ontario, Canada

${ }^{5}$ Endocrinology, Sunnybrooke Health Sciences Centre, Toronto, Ontario, Canada

Correspondence to

Dr Nir Melamed;

nir.melamed@sunnybrook.ca

\section{ABSTRACT}

Objective An increasing proportion of fetuses are exposed to antenatal corticosteroids (ACS). Despite their immediate beneficial effects, the long-term safety of ACS has been an ongoing source of concern. In the current study, we assessed the likelihood of neurodevelopmental problems among term infants exposed to ACS earlier in pregnancy compared with non-exposed term infants.

Design Retrospective cohort study (2006-2011). Median duration of follow-up was 7.8 (IQR 6.4-9.2) years.

Setting Population-based study, Ontario, Canada.

Participants All live singleton infants born at term $\left(\geq 37^{0 / 7}\right.$ weeks gestation) $(n=529205)$.

Exposure ACS during pregnancy.

Primary and secondary outcome measures $A$ composite of diagnostic or billing codes reflecting proven or suspected neurodevelopmental problems during childhood including audiometry testing, visual testing or physician service claim with a diagnosis code related to a suspected neurocognitive disorder.

Results At 5 years of age, the cumulative rate for the primary outcome was higher among infants exposed to ACS compared with non-exposed infants: $61.7 \%$ (3346/5423) vs $57.8 \%$ (302 520/523 782), respectively $(\mathrm{p}<0.001$; number needed to harm $(\mathrm{NNH})=25,95 \% \mathrm{Cl}$ 19 to 38; adjusted HR (aHR) 1.12, 95\% Cl 1.08 to 1.16). Similar findings were observed for each of the individual components of the primary outcome: $15.3 \%$ vs $12.7 \%$ for audiometry testing $(\mathrm{p}<0.001$; $\mathrm{NNH}=39,95 \% \mathrm{Cl} 29$ to 63 ; aHR $1.18,95 \% \mathrm{Cl} 1.11$ to 1.25$) ; 45.4 \%$ vs $43.5 \%$ for visual testing $(p=0.006$; $N N H=54,95 \% \mathrm{Cl} 31$ to 200 ; aHR 1.08, $95 \% \mathrm{Cl} 1.04$ to 1.12 ) and $25.8 \%$ vs $21.6 \%$ for suspected neurocognitive disorder $(\mathrm{p}<0.001 ; \mathrm{NNH}=24,95 \% \mathrm{Cl} 19$ to 33; aHR $1.16,95 \% \mathrm{Cl} 1.10$ to 1.21 ).

Conclusions We found an association among term infants between exposure to ACS during pregnancy and healthcare utilisation during childhood related to suspected neurocognitive and neurosensory disorders.

\section{INTRODUCTION}

Antenatal corticosteroids (ACS), which have been clearly shown to decrease neonatal mortality and short-term morbidity when administered to women at risk of preterm birth before $34^{0 / 7}$ weeks, ${ }^{1-5}$ are a common obstetrical
Strengths and limitations of this study

- Large sample size and population-based design in the setting of a single-payer universal healthcare system which allows capture of healthcare data from virtually all residents of the province of Ontario with no loss to follow-up or missing data.

- All infants were exposed to a single course of ACS.

- Although the large sample size allowed us to adjust for many of the known confounding variables, we cannot rule out the presence of unknown confounders.

- Another limitation is inherent to the use of administrative databases that are based on diagnostic or billing codes to determine outcomes which only indicate assessment for developmental problems rather than established diagnoses.

- Lack of data on the exact timing of exposure to ACS during pregnancy.

intervention. Nearly $10 \%$ of fetuses in some centres are exposed to ACS, ${ }^{6}$ a proportion that has been increasing over the last two decades ${ }^{67}$ Still, the long-term safety of ACS has been an ongoing source of concern given the presence of glucocorticoid receptors in the developing fetal brain which might thus be particularly vulnerable to ACS. ${ }^{8-10}$

In animal studies, exposure to ACS has been associated with delay in brain growth and development ${ }^{11-14}$ and with persistent changes in the hypothalamic-pituitaryadrenal (HPA) axis. ${ }^{15-20}$ Data regarding the long-term effects of ACS on human fetuses are less clear. Several randomised controlled trials have found that newborns exposed in utero to multiple courses of ACS have lower birth weight, length and head circumference compared with those exposed to only a single course of ACS. ${ }^{21-23}$ Although follow-up of these infants to the age of 2-3 years did not reveal a long-term effect on growth and composite neurodevelopmental 
outcome, ${ }^{24-26}$ one of these studies reported a non-significant but concerning increase in the risk of cerebral palsy. ${ }^{25}$ In addition, there are observational data linking exposure to multiple courses of ACS to increased rates of aggressive, destructive, distractible and hyperkinetic behaviour at both ages of 3 and 6 years. ${ }^{27}$ Finally, postnatal treatment of preterm infants with corticosteroids has been associated with increased risk of neurological impairment. ${ }^{12} 2829$ However, interpretation of human data is limited by insufficient power to detect differences in uncommon neurodevelopmental abnormalities and lack of a control group of infants not exposed to ACS. ${ }^{24-26}$

Another important factor that should be considered when interpreting available human studies on the longterm effects of ACS is that many of the infants who were included in these studies were born prematurely. ${ }^{24-26} 30-33$ It is likely that in this population of preterm infants, the immediate benefits of ACS compensate for the potential long-term adverse effects of ACS described above. ${ }^{34-36}$ However, it is possible that in the subgroup of fetuses that were at risk of preterm birth but were eventually born at term $\left(\geq 37^{0 / 7}\right.$ weeks $)$, in whom the short-term benefits of ACS are minimal or absent, any potential adverse long-term effects of ACS are more likely to be evident. This question, which is the focus of the current study, is highly relevant given that more than one-third of fetuses exposed to ACS are born at term. ${ }^{22}{ }^{23}$ Even more importantly, the recent recommendation to extend the use of ACS to the late preterm period $\left(34^{0 / 7} \text { to } 36^{5 / 7} \text { weeks }\right)^{37} 38$ might lead to a dramatic increase in the number of infants exposed in utero to ACS and an even greater increase in the proportion of fetuses exposed to ACS which will eventually be born at term.

However, despite the importance and relevance of this question, data on the long-term outcomes in this subgroup of term infants who were exposed to ACS are scarce. ${ }^{39-43}$ Currently available human data raise concerns that prior exposure to ACS, in term infants, might increase the risk of adverse neurodevelopmental outcome, specifically neurosensory disability. ${ }^{394}$ These concerns are supported by animal studies demonstrating neurosensory susceptibility to ACS in the form of delayed optic and auditory nerve myelination, ${ }^{14} 45$ decreased eye growth, ${ }^{46}$ decreased retinal thickness and maturation ${ }^{46}$ and abnormal auditory function. ${ }^{48}$ Other concerning long-term observations in term infants exposed to ACS include lower academic ability at school age, ${ }^{49}$ long-term dysfunction of the HPA axis $^{42} 43$ and abnormal brain anatomical findings such as cortical thinning which persist to early childhood. ${ }^{41}$

In the current study, we assessed the likelihood of neurodevelopmental problems among term infants exposed to ACS compared with term infants without such exposure.

\section{METHODS}

\section{Study population}

We conducted a population-based retrospective cohort study of all live singleton infants born at term $\left(\geq 37^{0 / 7}\right.$ weeks of gestation) in Ontario, Canada between January 2006 and December 2011. This period was chosen to provide a minimum follow-up of 5 years on all infants.

Multiple gestations, cases complicated by intrapartum asphyxia (defined as umbilical artery $\mathrm{pH}<7.1$ ), infants with genetic or major structural abnormalities and cases for whom data on exposure to ACS or on other variables were not available were excluded from the study. The rationale for excluding multiple gestations is the limited data regarding the effects of ACS in multiple gestations compared with singleton fetuses, ${ }^{50}{ }^{51}$ as well as the relatively small proportion of term fetuses born at full term.

\section{Data source}

Data were obtained from several provincial databases: (1) The Better Outcomes Registry E Network (BORN) Ontario, a province-wide registry of all births in Ontario, Canada. The database has a $100 \%$ capture for hospital births in Ontario. This database was used to identify the study population and to ascertain medical and obstetrical history, clinical information related to pregnancy including exposure to ACS, labour, birth and neonatal outcomes. (2) Healthcare administrative databases-Provincial healthcare administrative databases from the Ministry of Health and Long-Term Care are held at the Institute for Clinical Evaluative Sciences. These databases detail various aspects of health service utilisation by residents of the province and include: the Registered Persons Database, which records demographic information for all residents of Ontario; and the Ontario Health Insurance Plan provider service claims database, which records all fee-for-service billing and shadow-billing claims submitted by Ontario physicians and optometrists for in-patient or ambulatory consultations, assessments and diagnostic or therapeutic procedures. Because Ontario has a singlepayer universal healthcare system, these data capture virtually all care delivered to Ontario residents. Records from the administrative databases are linked deterministically using patients' encoded health card numbers which are consistent across data sources.

The use of data in this project was authorised under section 45 of Ontario's Personal Health Information Protection Act, which does not require review by a Research Ethics Board.

\section{Exposures and outcomes}

The primary exposure was administration of ACS during pregnancy and was ascertained from the BORN database. Although information about the preparation, dose and timing of exposure are not recorded in the BORN database, the Society of Obstetricians and Gynaecologists of Canada recommend administration of either betamethasone (2 doses of $12 \mathrm{mg}$ intramuscularly, 24 hours apart) or dexamethasone (4 doses of $6 \mathrm{mg}$ intramuscularly, 12 hours apart) between 24 and 34 weeks of gestation. ${ }^{52}$ The majority of women would have received betamethasone, as it is the most common type of ACS used in Canada. 


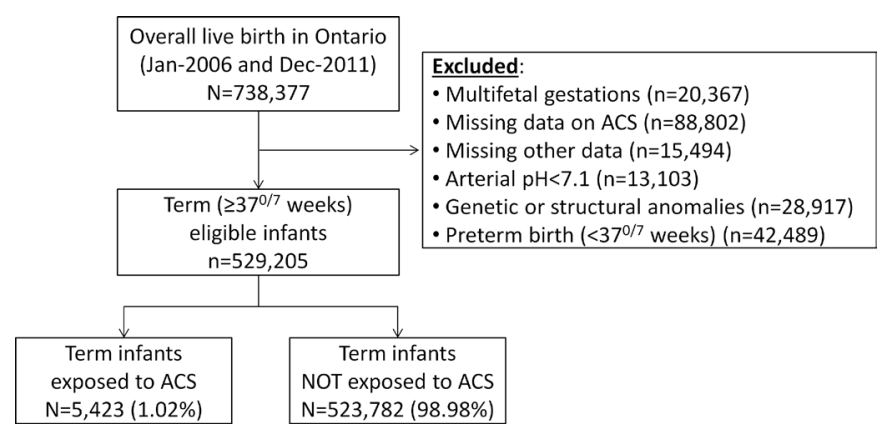

Figure 1 Description of the study groups. ACS, antenatal corticosteroids.

The primary outcome was a composite of any of the following that reflect proven or suspected neurodevelopmental problems: (1) audiometry testing - physician service claim for this testing outside the routine provincial infant screening programme for hearing deficits; (2) visual testing-any consultations or assessments from an ophthalmologist or optometrist; the follow-up period for this outcome was limited to the age of 5 years to exclude visual testing done as part of the routine screening initiated at school age or (3) suspected neurocognitive disorder-any physician service claim with a diagnosis code related to a suspected neurocognitive disorder. The codes used to define these outcomes are presented in online supplemental table $\mathrm{S} 1$. While service claims with these diagnostic codes do not necessarily prove that individuals have the corresponding diagnosis, a physician claim bearing one of these codes (particularly in infants and young children) suggests at minimum a concern about neurocognitive or neurosensory development that warranted clinical evaluation, although it is acknowledged that these outcomes are different from measured neurodevelopmental impairment. Secondary outcomes were each of the individual components of the primary outcome. While the follow-up period for visual testing was restricted to 5 years of age for the reasons discussed above, we did not restrict the follow-up period for the other outcomes since we do not anticipate that routine screening for visual impairment at the age of 5 years would impact the rate of audiometry testing or neurocognitive assessment.

\section{Statistical analysis}

The characteristics and outcomes of the ACS and control groups were compared using the Student's t-test and $\chi^{2}$ tests for continuous and categorical variables, respectively. The rate of each of the outcomes of interest in the ACS and control groups (expressed as number of events per 1000 person years) was stratified by age. Outcomes were also ascertained at the fixed time point of 5 years of age in order to get an estimate of the absolute risk difference at a specific time point. The number needed to harm $(\mathrm{NNH})$ was determined for each of the outcomes at 5 years of age.

The association of ACS exposure with the primary and secondary outcomes was assessed using the Cox proportional hazards model, with adjustment for potential confounding variables including maternal age, week of gestation, parity, income (assigned ecologically based on neighbourhood-level household income, divided into province-wide quintiles), chronic hypertension, pregestational diabetes, hypertensive complications of pregnancy, gestational diabetes, preterm premature rupture of membranes, induction of labour, mode of delivery, infant sex, birth weight $<10$ th centile, 5 min Apgar $<7$, resuscitation at birth and admission to neonatal intensive care unit (NICU). As a sensitivity analysis, we included repeated analysis after exclusion of infants who were either admitted to the NICU or had a birth weight $<10$ th percentile.

Data were analysed using the SAS Enterprise Guide statistical software V.6.1. Differences were considered significant for a $\mathrm{p}$ value $<0.05$.

\section{Patient and public involvement}

Patients were not involved in the research question, design, or conduction of the current study.

\section{RESULTS}

\section{Characteristics of the study population}

A total of 738377 live singleton infants were born in Ontario during the study period. Of the 529205 infants who met the study criteria, $5432(1.02 \%)$ were exposed to ACS during pregnancy and were compared with 523782 $(98.98 \%)$ infants not exposed to ACS (figure 1).

Maternal baseline characteristics are presented in table 1. There were significant differences between the groups in maternal age, parity, income, medical disorders, induction of labour and mode of delivery. However, for many of these characteristics the absolute differences between the groups were very small (table 1). Infants in the ACS group were born at an earlier gestational age, had a lower mean birth weight, were more likely to have a birth weight below the 10th percentile for gestational age and were slightly more likely to require resuscitation at birth and admission to the NICU compared with infants not exposed to ACS (table 1).

\section{Exposure to ACS and outcomes: unadjusted analysis}

The median duration of follow-up for the entire cohort was 7.8 (IQR 6.4-9.2) years. At 5 years of age, term infants exposed to ACS were significantly more likely to have the primary composite outcome ( $61.7 \%$ vs $57.8 \%)$, due to a higher rate of audiometry testing ( $15.3 \%$ vs $12.7 \%)$, visual testing $(45.4 \%$ vs $43.5 \%)$ and suspected neurocognitive disorder $(25.8 \%$ vs $21.6 \%)$ compared with term infants not exposed to ACS (table 2). The NNH was lowest for suspected neurocognitive disorder $(\mathrm{NNH}=24,95 \%$ CI 19 to 33), followed by the composite outcome $(\mathrm{NNH}=25$, $95 \%$ CI 19 to 38$)$ and audiometry testing $(\mathrm{NNH}=39$, $95 \%$ CI 29 to 63$)$.

\section{Exposure to ACS and outcomes: adjusted analysis}

Given the differences in baseline characteristics, we assessed the association between exposure to ACS and 
Table 1 Maternal and neonatal baseline characteristics of the study and control groups

\begin{tabular}{|c|c|c|c|}
\hline Characteristic & $\begin{array}{l}\text { Term infants exposed to } \\
\text { ACS } \\
n=5423\end{array}$ & $\begin{array}{l}\text { Term infants } \\
\text { NOT exposed to ACS } \\
n=523782\end{array}$ & $P$ value \\
\hline Maternal age (years) & $29.50 \pm 5.87$ & $29.97 \pm 5.48$ & $<0.001$ \\
\hline$>35$ years & 847 (15.6\%) & $82860(15.8 \%)$ & 0.69 \\
\hline Parity & & & 0.002 \\
\hline 0 (nulliparity) & 2298 (42.4\%) & 226739 (43.3\%) & \\
\hline 2 & 777 (14.3\%) & $72454(13.8 \%)$ & \\
\hline$\geq 3$ & $421(7.8 \%)$ & $34339(6.6 \%)$ & \\
\hline Income quintile* & & & 0.02 \\
\hline Q1 (lowest) & $1308(24.1 \%)$ & $117423(22.4 \%)$ & \\
\hline Q5 (highest) & $842(15.5 \%)$ & $84610(16.2 \%)$ & \\
\hline Chronic hypertension & $60(1.1 \%)$ & $3317(0.6 \%)$ & $<0.001$ \\
\hline Pregestational diabetes & $126(2.3 \%)$ & 7467 (1.4\%) & $<0.001$ \\
\hline Hypertensive complications $†$ & $298(5.5 \%)$ & $22552(4.3 \%)$ & $<0.001$ \\
\hline Gestational diabetes & $345(6.4 \%)$ & $23961(4.6 \%)$ & $<0.001$ \\
\hline Gestational age at birth & & & $<0.001$ \\
\hline $37^{0 / 7}$ to $38^{6 / 7}$ weeks & $2598(47.9 \%)$ & $148843(28.4 \%)$ & \\
\hline $39^{0 / 7}$ to $40^{6 / 7}$ weeks & $2396(44.2 \%)$ & $301183(57.5 \%)$ & \\
\hline$\geq 41^{0 / 7}$ weeks & $429(7.9 \%)$ & $73756(14.1 \%)$ & \\
\hline Male sex & 2738 (50.5\%) & $265003(50.6 \%)$ & 0.88 \\
\hline 5 min Apgar $<7$ & $42(0.8 \%)$ & $3714(0.7 \%)$ & 0.57 \\
\hline Resuscitation at birth & $856(15.8 \%)$ & 75305 (14.4\%) & 0.003 \\
\hline NICU admission & 179 (3.3\%) & $10121(1.9 \%)$ & $<0.001$ \\
\hline
\end{tabular}

Data are presented as mean \pm SD or $\mathrm{n}(\%)$.

*Measured ecologically as the neighbourhood household income, divided into quintiles.

†Refers to gestational hypertension or pre-eclampsia.

$\ddagger$ Based on the national reference charts by Kramer et al. ${ }^{57}$

ACS, antenatal corticosteroids; NICU, neonatal intensive care unit

the primary and secondary outcomes while adjusting for potential confounding variables using Cox proportional hazards analysis (table 3). Exposure to ACS was associated with an increased risk of the primary composite outcome (aHR $1.12,95 \%$ CI 1.08 to 1.16 ), audiometry testing (aHR $1.18,95 \%$ CI 1.11 to 1.25 ), visual testing (aHR 1.08, $95 \%$ CI 1.04 to 1.12 ), suspected neurocognitive disorder (aHR 1.16, 95\% CI 1.10 to 1.21 ) and combination of both audiometry testing and suspected neurocognitive disorder (aHR 1.23, 95\% CI 1.14 to 1.43) (table 3, overall cohort). Findings remained unchanged when infants who were either admitted to the NICU or had a birth weight $<10$ th percentile were excluded from the analysis (table 3).

Finally, to determine the timing during childhood at which these differences between term infants exposed versus not exposed to ACS were most pronounced, we compared the rates of each of the outcomes of interest between the two groups stratified by age (figures 2-4). For audiometry testing, visual testing and suspected neurocognitive disorders, the differences between the 
Table 2 Unadjusted rates of the primary and secondary outcomes at 5 years of age in the antenatal corticosteroids and control groups

\begin{tabular}{|c|c|c|c|c|}
\hline \multirow[b]{2}{*}{ Outcome } & \multicolumn{4}{|c|}{ Cumulative rate of outcome at a fixed time point of 5 years of age } \\
\hline & $\begin{array}{l}\text { Term infants exposed } \\
\text { to ACS } \\
\mathrm{n}=5423\end{array}$ & $\begin{array}{l}\text { Term infants } \\
\text { NOT exposed to ACS } \\
\mathrm{n}=523782\end{array}$ & $P$ value & $\begin{array}{l}\text { NNH } \\
(95 \% \mathrm{Cl})\end{array}$ \\
\hline Composite long-term outcome & $3346(61.7 \%)$ & $302520(57.8 \%)$ & $<0.001$ & 25 (19 to 38$)$ \\
\hline Audiometry testing & $827(15.3 \%)$ & $66555(12.7 \%)$ & $<0.001$ & 39 (29 to 63$)$ \\
\hline Visual testing & $2461(45.4 \%)$ & $227948(43.5 \%)$ & 0.006 & 54 (31 to 200$)$ \\
\hline $\begin{array}{l}\text { Suspected neurocognitive } \\
\text { disorder }\end{array}$ & $1397(25.8 \%)$ & $113181(21.6 \%)$ & $<0.001$ & 24 (19 to 33) \\
\hline
\end{tabular}

Significant $\mathrm{p}$ values are emphasized in bold font.

ACS, antenatal corticosteroids; $\mathrm{NNH}$, number needed to harm.

groups emerged early in life and persisted up to the age of 6,3 and 7 years, respectively.

\section{DISCUSSION}

Principal findings of this study

In the current study we found that term infants exposed to ACS before 34 weeks of gestation were more likely to undergo audiometry testing, visual testing and assessment for a suspected neurocognitive disorder compared with term infants not exposed to ACS. Although our outcomes do not necessarily prove that individuals have the corresponding diagnosis (ie, hearing loss, visual loss or neurocognitive disorders), these assessments (particularly in infants and young children) suggest at minimum a concern about a neurosensory or neurocognitive disorder that warranted clinical evaluation. Thus, these findings seem to provide support for a potential adverse effect of
ACS on these developmental pathways, especially when taken together with previous studies that support such an association.

\section{Strengths and weaknesses}

The main strengths of the current study relates to the large sample size and population-based design in the setting of a single-payer universal healthcare system which allows capture of healthcare data from virtually all residents of the province. Additional strengths include the use of a cohort of infants born at term who were exposed to a single course of ACS, the availability of reliable information regarding the exposure and important potential confounding variables.

Limitations of the current study include the potential for residual confounding. Although the large sample size allowed us to adjust for many of the known confounding variables, we cannot rule out the presence of unknown

Table 3 Risk of adverse long-term outcome by exposure to antenatal corticosteroids: time-to-event analysis

\section{Risk of the corresponding outcome in term infants exposed to ACS (using non- exposed infants as reference) \\ (Hazard ratio $(95 \% \mathrm{Cl})$ )}

\begin{tabular}{lll} 
Outcome & Overall cohort & $\begin{array}{l}\text { NICU admission or birth weight }<\text { 10th } \\
\text { percentile }\end{array}$ \\
\hline Composite long-term outcome & $1.12(1.08$ to 1.16$)$ & $1.12(1.08$ to 1.16$)$ \\
\hline Audiometry testing & $1.18(1.11$ to 1.25$)$ & $1.18(1.11$ to 1.26$)$ \\
\hline $\begin{array}{l}\text { Visual testing } \\
\text { Suspected neurocognitive disorder }\end{array}$ & $1.08(1.04$ to 1.12$)$ & $1.03(1.03$ to 1.12$)$ \\
$\begin{array}{l}\text { Audiometry testing AND suspected } \\
\text { neurocognitive disorder }\end{array}$ & $1.23(1.10$ to 1.21$)$ & $1.17(1.11$ to 1.23$)$ \\
\hline
\end{tabular}

Values reflect the results of Cox proportional hazards model.

*Model adjusted for the following variable: maternal age (as a continuous variable), week of gestation, parity, income, chronic hypertension, pregestational diabetes, hypertensive complications, gestational diabetes, preterm premature rupture of membranes, induction of labour, mode of delivery, infant sex, birth weight $<10$ th percentile, $5 \mathrm{~min}$ Apgar $<7$, resuscitation at birth and admission to NICU.

†Model adjusted for the following variable: maternal age (as a continuous variable), week of gestation, parity, income, chronic hypertension, pregestational diabetes, hypertensive complications, gestational diabetes, preterm premature rupture of membranes, induction of labour, mode of delivery, infant sex, 5 min Apgar $<7$ and resuscitation at birth.

ACS, antenatal corticosteroids; NICU, neonatal intensive care unit. 


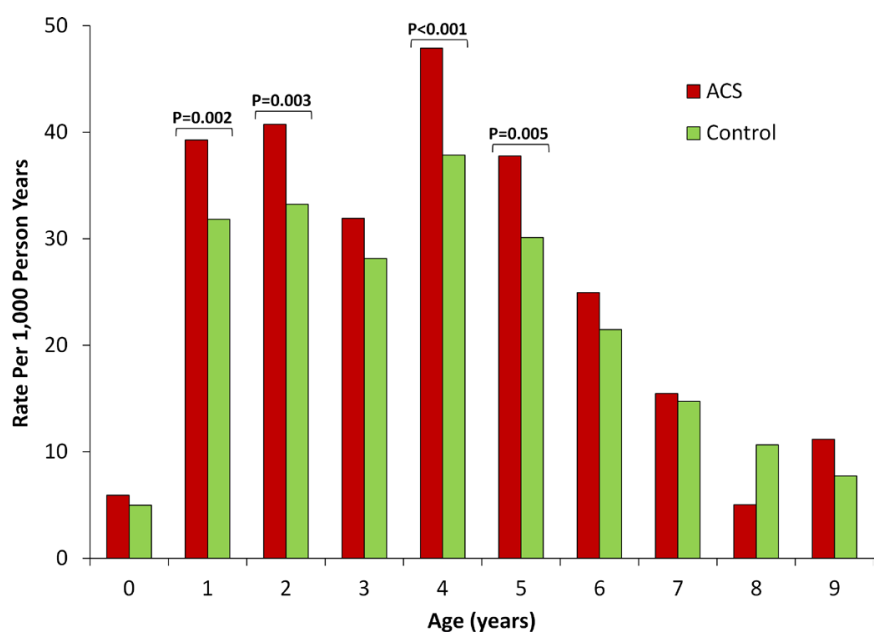

Figure 2 Rate of audiometry testing by exposure to antenatal corticosteroids stratified by age. Unadjusted rate of outcome (expressed as number of events per 1000 person years) is compared between term infants exposed (red bars) versus non exposed (green bars) to antenatal corticosteroids stratified by child age. $P$ values are presented for statistically significant differences (defined as $\mathrm{p}<0.05$ ).

confounders such as the indication for administration of ACS, exposure to other medications (such as tocolytic agents) during pregnancy and other genetic and environmental factors that may affect infant development. Another limitation is inherent to the use of administrative databases that are based on diagnostic or billing codes to determine outcomes which only indicate assessment for developmental problems rather than established diagnoses. Other limitations include the relatively high rate of the composite outcome, the lack of data on the exact timing of exposure to ACS during pregnancy and the fact

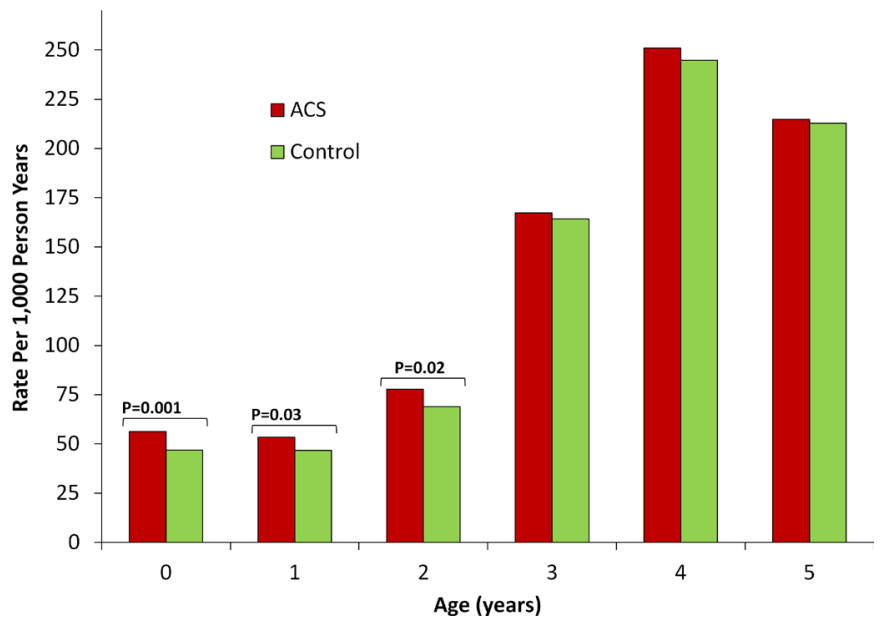

Figure 3 Rate of visual testing by exposure to antenatal corticosteroids stratified by age. Unadjusted rate of outcome (expressed as number of events per 1000 person years) is compared between term infants exposed (red bars) versus non exposed (green bars) to antenatal corticosteroids stratified by child age. $P$ values are presented for statistically significant differences (defined as $\mathrm{p}<0.05$ ).

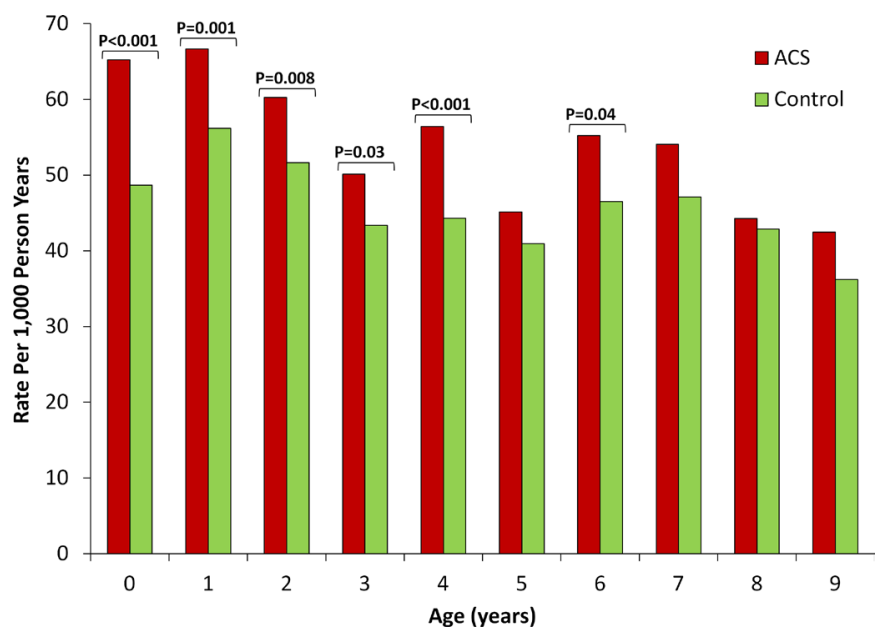

Figure 4 Rate of suspected neurocognitive disorder by exposure to antenatal corticosteroids stratified by age. Unadjusted rate of outcome (expressed as number of events per 1000 person years) is compared between term infants exposed (red bars) versus non exposed (green bars) to antenatal corticosteroids stratified by child age. $P$ values are presented for statistically significant differences (defined as $\mathrm{p}<0.05)$.

that data on ACS were missing for a considerable proportion of the cohort.

\section{Strengths and weaknesses in relation to other studies}

Data on the long-term effects of ACS in infants who ended up being born at term are scarce but our findings are consistent with available data. One important source of data regarding the long-term outcome of term infants who were exposed to ACS comes from the 5-year follow-up study of the Multiple Courses of Antenatal Corticosteroids for Preterm Birth Study (MACS-5).$^{39} 44$ MACS was a multicentre international randomised clinical trial that compared multiple courses of ACS with a single course in women at risk of preterm birth. ${ }^{23}$ Of the original cohort, 1728 children were available for follow-up at the age of 5 years. Overall, the rate of the primary outcome (defined as death or neurodevelopmental disability involving neuromotor, neurosensory, neurocognitive or neurobehavioral functions) was similar between the multiple-course and single-course groups. However, in a subgroup analysis of the infants born at term, exposure to multiple course of ACS was associated with increased odds of the primary composite outcome and almost fourfold increased odds of neurosensory disability. ${ }^{394}$ The interpretation of these findings is limited by the fact that the 'exposure' in that study involved two or more courses of ACS and by the lack of a control group of children unexposed to ACS. The Antenatal Steroids for Term Elective Caesarean Section trial demonstrated that administration of ACS prior to elective caesarean delivery at term reduced shortterm respiratory morbidity. ${ }^{49}$ However, in their long-term follow-up study, children in the ACS group were twice as likely to be rated in the lowest quartile of academic ability by their school at age $8-15$ years. These findings align 
with several smaller studies on the long-term outcomes of term infants in which exposure to ACS was associated with significant bilateral cortical thinning at the age of $6-10$ years ${ }^{41}$ and disruption of the circadian regulation of the HPA axis in school-aged children. ${ }^{42}$

\section{CONCLUSION}

Our findings support the increasing concerns regarding the potential adverse long-term effects of fetal exposure to ACS. This question is highly relevant given the considerable proportion of ACS-exposed fetuses who subsequently are born at term, a proportion that is likely to increase given the recent recommendations to administer ACS to all women at risk of preterm birth during the late-preterm period. ${ }^{38}$ When women present in preterm labour, we appreciate that sometimes it is difficult to predict who will actually give birth preterm and may thus benefit from ACS. Still, by not recognising that there is a potential for long-term risk from ACS exposure, clinicians may be too liberal with the use of ACS. ${ }^{53}{ }^{54}$ We believe that greater awareness regarding the potential long-term adverse effects of ACS, along with the development of better tools for the prediction of preterm birth, ${ }^{55}$ may assist clinicians in decision-making regarding administration of ACS in those cases where the likelihood of imminent preterm birth is relatively low. Finally, this information, if confirmed by additional prospective studies, may be important for guideline writers when deciding on the risk-benefit ratio of a policy of routine administration of ACS during the late-preterm period. Still, it should be emphasised that the findings described above merely represent an association rather than causation, and the interpretation of these findings is limited by the limitations described above.

Contributors NM, EA, BS, DR and JB conceptualised and designed the study, were involved in the analysis and interpretation of the data, drafted the initial manuscript, reviewed and revised the manuscript. KM and AZ were involved in the analysis and interpretation of the data, reviewed the manuscript and provided significant contribution to the revised manuscript. All authors approved the final manuscript as submitted and agree to be accountable for all aspects of the work.

Funding The authors have not declared a specific grant for this research from any funding agency in the public, commercial or not-for-profit sectors.

Competing interests None declared.

Patient consent for publication Not required.

Provenance and peer review Not commissioned; externally peer reviewed.

Data availability statement No data are available.

Open access This is an open access article distributed in accordance with the Creative Commons Attribution Non Commercial (CC BY-NC 4.0) license, which permits others to distribute, remix, adapt, build upon this work non-commercially, and license their derivative works on different terms, provided the original work is properly cited, appropriate credit is given, any changes made indicated, and the use is non-commercial. See: http://creativecommons.org/licenses/by-nc/4.0/.

\section{ORCID iD}

Donald Redelmeier http://orcid.org/0000-0003-4147-3544
REFERENCES

1 Liggins GC, Howie RN. A controlled trial of antepartum glucocorticoid treatment for prevention of the respiratory distress syndrome in premature infants. Pediatrics 1972;50:515-25.

2 Effect of corticosteroids for fetal maturation on perinatal outcomes. NIH consensus statement 1994;12:1-24.

3 Roberts D, Dalziel S. Antenatal corticosteroids for accelerating fetal lung maturation for women at risk of preterm birth. The Cochrane database of systematic reviews 2006.

4 Crowley P, Chalmers I, Keirse MJ. The effects of corticosteroid administration before preterm delivery: an overview of the evidence from controlled trials. Br J Obstet Gynaecol 1990;97:11-25.

5 Crowley PA. Antenatal corticosteroid therapy: a meta-analysis of the randomized trials, 1972 to 1994. Am J Obstet Gynecol 1995;173:322-35.

6 Grzeskowiak LE, Grivell RM, Mol BW. Trends in receipt of single and repeat courses of antenatal corticosteroid administration among preterm and term births: a retrospective cohort study. Aust N Z J Obstet Gynaecol 2017;57:643-50.

7 Razaz N, Skoll A, Fahey J, et al. Trends in optimal, suboptimal, and questionably appropriate receipt of antenatal corticosteroid prophylaxis. Obstetrics \& Gynecology 2015;125:288-96.

8 Patel PD, Katz M, Karssen AM, et al. Stress-Induced changes in corticosteroid receptor expression in primate hippocampus and prefrontal cortex. Psychoneuroendocrinology 2008;33:360-7.

9 Jobe AH, Goldenberg RL. Antenatal corticosteroids: an assessment of anticipated benefits and potential risks. Am J Obstet Gynecol 2018;219:62-74.

10 Sloboda D, Challis J, Moss T, et al. Synthetic glucocorticoids: antenatal administration and long-term implications. Curr Pharm Des 2005;11:1459-72.

11 Huang WL, Beazley LD, Quinlivan JA, et al. Effect of corticosteroids on brain growth in fetal sheep. Obstetrics and gynecology 1999;94:213-8.

12 Whitelaw A, Thoresen M. Antenatal steroids and the developing brain. Arch Dis Child Fetal Neonatal Ed 2000;83:154F-7.

13 Uno H, Lohmiller L, Thieme C, et al. Brain damage induced by prenatal exposure to dexamethasone in fetal rhesus macaques. I. hippocampus. Developmental Brain Research 1990;53:157-67.

14 Rittenschober-Böhm J, Rodger J, Jobe AH, et al. Antenatal corticosteroid exposure disrupts myelination in the auditory nerve of preterm sheep. Neonatology 2018;114:62-8.

15 Kemp MW, Newnham JP, Challis JG, et al. The clinical use of corticosteroids in pregnancy. Human reproduction update 2016;22:240-59.

16 Braun T, Challis JR, Newnham JP, et al. Early-Life glucocorticoid exposure: the hypothalamic-pituitary-adrenal axis, placental function, and long-term disease risk. Endocr Rev 2013;34:885-916.

17 Reynolds RM. Programming effects of glucocorticoids. Clin Obstet Gynecol 2013;56:602-9.

18 Reynolds RM. Glucocorticoid excess and the developmental origins of disease: two decades of testing the hypothesis-2012 Curt Richter Award winner. Psychoneuroendocrinology 2013;38:1-11.

19 Moisiadis VG, Matthews SG. Glucocorticoids and fetal programming Part 1: outcomes. Nat Rev Endocrinol 2014;10:391-402.

20 Matthews SG. Antenatal glucocorticoids and programming of the developing CNS. Pediatr Res 2000;47:291-300.

21 Crowther CA, Haslam RR, Hiller JE, et al. Australasian collaborative trial of repeat doses of steroids study $\mathrm{G}$. neonatal respiratory distress syndrome after repeat exposure to antenatal corticosteroids: a randomised controlled trial. Lancet 2006;367:1913-9.

22 Wapner RJ, Sorokin Y, Thom EA, et al. Single versus weekly courses of antenatal corticosteroids: evaluation of safety and efficacy. Am J Obstet Gynecol 2006;195:633-42.

23 Murphy KE, Hannah ME, Willan AR, et al. Multiple courses of antenatal corticosteroids for preterm birth (MACS): a randomised controlled trial. The Lancet 2008;372:2143-51.

24 Crowther CA, Doyle LW, Haslam RR, et al. Outcomes at 2 years of age after repeat doses of antenatal corticosteroids. New England Journal of Medicine 2007;357:1179-89.

25 Wapner RJ, Sorokin Y, Mele L, et al. Long-term outcomes after repeat doses of antenatal corticosteroids. $N$ Engl J Med 2007;357:1190-8.

26 Asztalos EV, Murphy KE, Hannah ME, et al. Multiple courses of antenatal corticosteroids for preterm birth study: 2-year outcomes. Pediatrics 2010;126:e1045-55.

27 French NP, Hagan R, Evans SF, et al. Repeated antenatal corticosteroids: effects on cerebral palsy and childhood behavior. Am J Obstet Gynecol 2004;190:588-95. 
28 O'shea TM, Doyle LW. Perinatal glucocorticoid therapy and neurodevelopmental outcome: an epidemiologic perspective. Seminars in Neonatology 2001;6:293-307.

29 Halliday HL, Ehrenkranz RA, Doyle LW. Early ( $<8$ days) postnatal corticosteroids for preventing chronic lung disease in preterm infants. Cochrane Database Syst Rev 2010;(1):CD001146.

30 Doyle LW, Ford GW, Rickards AL, et al. Antenatal corticosteroids and outcome at 14 years of age in children with birth weight less than 1501 Grams. Pediatrics 2000;106:E2.

31 Waters TP, Silva N, Denney JM, et al. Neonatal hearing assessment in very low birth weight infants exposed to antenatal steroids. $J$ Perinatol 2008;28:67-70.

32 Ishikawa H, Miyazaki K, Ikeda T, et al. The effects of antenatal corticosteroids on short- and long-term outcomes in small-forgestational-age infants. Int J Med Sci 2015;12:295-300.

33 Miyazaki K, Furuhashi M, Ishikawa K, et al. Long-term outcomes of antenatal corticosteroids treatment in very preterm infants after chorioamnionitis. Arch Gynecol Obstet 2015;292:1239-46.

34 Roberts D, Brown J, Medley N, et al. Antenatal corticosteroids for accelerating fetal lung maturation for women at risk of preterm birth. Cochrane Database Syst Rev 2017;3.

35 Crowther CA, Middleton PF, Voysey M, et al. Effects of repeat prenatal corticosteroids given to women at risk of preterm birth: an individual participant data meta-analysis. PLoS Med 2019;16:e1002771.

36 Crowther CA, McKinlay CJD, Middleton P, et al. Repeat doses of prenatal corticosteroids for women at risk of preterm birth for improving neonatal health outcomes. Cochrane Database Syst Rev 2015;24.

37 Gyamfi-Bannerman C, Thom EA, Blackwell SC, et al. Antenatal betamethasone for women at risk for late preterm delivery. $N$ Engl $J$ Med 2016;374:1311-20.

38 ACOG Practice Advisory. Antenatal corticosteroid administration in the late preterm period, 2016.

39 Asztalos EV, Murphy KE, Willan AR, et al. Multiple courses of antenatal corticosteroids for preterm birth study: outcomes in children at 5 years of age (MACS-5). JAMA pediatrics 2013;167:1102-10.

40 Stutchfield PR, Whitaker R, Gliddon AE, et al. Behavioural, educational and respiratory outcomes of antenatal betamethasone for term caesarean section (ASTECS trial). Arch Dis Child Fetal Neonatal Ed 2013;98:F195-F200.

41 Davis EP, Sandman CA, Buss C, et al. Fetal glucocorticoid exposure is associated with preadolescent brain development. Biol Psychiatry 2013;74:647-55

42 Edelmann MN, Sandman CA, Glynn LM, et al. Antenatal glucocorticoid treatment is associated with diurnal cortisol regulation in term-born children. Psychoneuroendocrinology 2016;72:106-12.
43 Alexander N, Rosenlöcher F, Stalder T, et al. Impact of antenatal synthetic glucocorticoid exposure on endocrine stress reactivity in term-born children. J Clin Endocrinol Metab 2012;97:3538-44.

44 Asztalos E, Willan A, Murphy K, et al. Association between gestational age at birth, antenatal corticosteroids, and outcomes at 5 years: multiple courses of antenatal corticosteroids for preterm birth study at 5 years of age (MACS-5). BMC Pregnancy Childbirth 2014;14:272.

45 Dunlop SA, Archer MA, Quinlivan JA, et al. Repeated prenatal corticosteroids delay myelination in the ovine central nervous system. J Matern Fetal Med 1997;6:309-13.

46 Quinlivan JA, Beazley LD, Evans SF, et al. Retinal maturation is delayed by repeated, but not single, maternal injections of betamethasone in sheep. Eye 2000;14:93-8.

47 Quinlivan JA, Beazley LD, Braekevelt CR, et al. Repeated ultrasound guided fetal injections of corticosteroid alter nervous system maturation in the ovine fetus. J Perinat Med 2001;29:112-27.

48 Church MW, Adams BR, Anumba Jl, et al. Repeated antenatal corticosteroid treatments adversely affect neural transmission time and auditory thresholds in laboratory rats. Neurotoxicol Teratol 2012;34:196-205.

49 Stutchfield P, Whitaker R, Russell I. Antenatal steroids for term elective caesarean section research $\mathrm{T}$. antenatal betamethasone and incidence of neonatal respiratory distress after elective caesarean section: pragmatic randomised trial. BMJ 2005;331.

50 Boghossian NS, McDonald SA, Bell EF, et al. Association of antenatal corticosteroids with mortality, morbidity, and neurodevelopmental outcomes in extremely preterm multiple gestation infants. JAMA Pediatr 2016:170:593-601.

51 Melamed N, Shah J, Yoon EW, et al. The role of antenatal corticosteroids in twin pregnancies complicated by preterm birth. Am J Obstet Gynecol 2016;215:482.e1-482.

52 Crane J, Armson A, Brunner M, et al. Antenatal corticosteroid therapy for fetal maturation. Obstet Gynecol 2003;25:45-52.

53 Skoll A, Ferreira E, Pedneault L, et al. Do we use too much antenatal betamethasone? J Obstet Gynaecol Can 2002;24:330-4.

54 Melamed N, Shah J, Soraisham A, et al. Association between antenatal corticosteroid administration-to-birth interval and outcomes of preterm neonates. Obstetrics \& Gynecology 2015;125:1377-84

55 Alsayegh E, Barrett J, Melamed N. Optimal timing of antenatal corticosteroids in women with bleeding placenta previa or low-lying placenta. J Matern Fetal Neonatal Med 2018:1-7.

56 Melamed N, Hiersch L, Domniz N, et al. Predictive value of cervical length in women with threatened preterm labor. Obstet Gynecol 2013;122:1279-87.

57 Kramer MS, Platt RW, Wen SW, et al. A new and improved population-based Canadian reference for birth weight for gestational age. Pediatrics 2001;108:E35. 